\title{
Solid Phase Microextraction Techniques Used for Gas Chromatography: A Review
}

\author{
Stefano Dugheri ${ }^{1 *}$, Nicola Mucci $^{2}$, Alessandro Bonari ${ }^{2}$, Giorgio Marrubini ${ }^{3}$, Giovanni Cappelli ${ }^{2}$, \\ Daniela Ubiali $^{3}$, Marcello Campagna ${ }^{4}$, Manfredi Montalti ${ }^{2}$ and Giulio Arcangeli ${ }^{2}$ \\ Industrial Hygiene and Toxicology Laboratory, Careggi University Hospital, Florence, Italy \\ ${ }^{2}$ Department of Experimental and Clinical Medicine, University of Florence, Florence, Italy \\ Department of Drug Sciences, University of Pavia, Pavia, Italy \\ ${ }^{4}$ Department of Medical Sciences and Public Health, University of Cagliari, Cagliari, Italy
}

Received: 10 December 2018; accepted: 10 December 2018

\begin{abstract}
In the last decade, the development and adoption of greener and sustainable microextraction techniques have been proved to be an effective alternative to classical sample preparation procedures. In this review, 10 commercially available solid-phase microextraction systems are presented, with special attention to the appraisal of their analytical, bioanalytical, and environmental engineering. This review provides an overview of the challenges and achievements in the application of fully automated miniaturized sample preparation methods in analytical laboratories. Both theoretical and practical aspects of these environment-friendly preparation approaches are discussed. The application of chemometrics in method development is also discussed. We are convinced that green analytical chemistry will be really useful in the years ahead. The application of cheap, fast, automated, "clever", and environmentally safe procedures to environmental, clinical, and food analysis will improve significantly the quality of the analytical data.
\end{abstract}

Keywords: solid-phase microextraction, gas chromatography, robotic autosampler, large volume injection, chemometrics

\section{Introduction}

Gas chromatography (GC) and liquid chromatography (LC) are the standard instrumentation for testing most of the analytes in all application fields of analytical chemistry. Together, these two techniques account for the larger proportion of the world's sales in analytical instrumentation, and their forecast market trends are substantially steady for the next years. The global GC market is expected to reach USD 3.67 billion by 2022, up from 2.64 billion in 2016, at a Compound Annual Growth Rate (CAGR) of $6.2 \%$ [1]. Similarly, the LC market is expected to reach USD 4.13 billion by 2021, up from 3.23 billion in 2016, growing slightly more slowly at a CAGR of 5.1\% [2]. North America, which held over 39\% of the GC market in 2016 [3], will retain its dominance, with sales predicted to soar through 2022; at the same time, Europe will continue to be the second largest GC market [4].

This substantial growth in the chromatographic instrumentation manufacturing industry has resulted in a booming demand for technicians with expertise. However, chromatographic instruments are complex, and despite the technological innovations in devices, the availability of skilled labor is still an issue. Moreover, these instruments also require timely standardization protocols and maintenance procedures that need personnel trained and updated continuously. Above all, sample preparation is a critical node, especially for GC: it is time-consuming, labor-intensive and error prone. More than $80 \%$ of analysis time is spent collecting and preparing samples. Consequently, in GC, innovative sample prep and introduction techniques are expected to improve dramatically the technique.

*Author for correspondence: stefano.dugheri@unifi.it.
Miniaturization is a technological trend that has been implemented every year more in all kinds of analytical instrumentation. Traditionally, large bench-top instruments such as Raman spectrophotometers and GC-MS systems with thermal desorption sample injection are nowadays made available as portable instruments [5-8], something unimaginable only a few years ago. Miniaturization has been increasingly applied to GC for the last 10 years, resulting in savings in both time and costs throughout the sampling process.

The Solid Phase Microextraction (SPME) technique was invented by Pawliszyn in 1989 [9]. Solid-phase extraction sampling is performed using a fiber, housed in a stainless-steel needle, coated with a sorbent phase that can be liquid or solid. This powerful miniaturized sampling technique can be used for sampling a wide variety of analytes, capturing them from matrices that can be either gases or liquids [10-14]. SPME is considered one of the major breakthroughs in the 20th-century analytical chemistry [15]. SPME was initially distributed by Supelco (Bellefonte, USA). Since 2009, other devices have been introduced onto the market that were designed to tackle two major issues, namely, the fragility of the fiber, which could be easily damaged during use, and full automation of SPME-based injectors in GC. In fact, in that year, a new generation of SPME fibers, the SPME Fast Fit Fiber Assemblies (FFA-SPME), was developed by Chromline (Prato, Italy) in cooperation with Supelco, which expanded the applicability of SPME [16]; this new set-up allowed automatic exchange of SPME fibers by using a dedicated autosampler (e.g., the Multi Fiber Exchange, MFX developed by GERSTEL together with Supelco).

At the same time, other companies were also working on SPME technologies using the same concept: the PAL SPME Arrows (Restek Corporation, Bellefonte, USA) were designed

This is an open-access article distributed under the terms of the Creative Commons Attribution-NonCommercial 4.0 International License (https://creativecommons.org/licenses/by-nc/4.0/), which permits unrestricted use, distribution, and reproduction in any medium for non-commercial purposes, provided the original author and source are credited, a link to the CC License is provided, and changes - if any - are indicated. 
to contain greater phase volume as compared with normal SPME fibers, which allowed more target analytes to be extracted. The SPME Arrows also had sorbent fibers built inside a stainless-steel cylinder equipped with an inner rod and outer sheath to protect the sorbent phase from mechanical damage and ensure minimal analyte loss during sample transfer [17].

A completely different concept was used in the design of the Microextraction by Packed Sorbent (MEPS) system developed by SGE Analytical Science (Trajan Scientific and Medical, Ringwood Victoria, Australia) in collaboration with Mohamed Abdel-Rehim from AstraZeneca. The MEPS is a miniaturized embodiment of SPE. The MEPS sampling device uses the same sorbents as conventional SPE columns. However, in MEPS, the sorbent (1-4 mg) is either incorporated as a plug into the barrel of a microsyringe for liquids (100-250 $\mu \mathrm{L})$ or inserted between the needle and the barrel as a cartridge. The MEPS allows small volume sample manipulations manually and in combination with GC and LC autosamplers [18-20].

Another microdevice developed for sampling is the Stir Bar Sorptive Extraction (SBSE) or Twister ${ }^{\circledR}$ (GERSTEL GmbH \& Co.KG, Mülheim an der Ruhr, Germany). This is a magnetic stir bar coated with a partitioning sorbent phase. The stir bar can be used to extract analytes from liquid samples or from the headspace (HS) of a solution before (e.g., thermal) desorption and injection into the GC system for analysis [21, 22].

The so-called in-tube or in-needle extraction techniques have also been developed in the meantime. These techniques for microextraction can be classified broadly in two groups according to Jochmann et al. [23]: methods that use a needle which is coated on the inner surface with the sorbent phase and needles or tubes packed with a sorbent material.

The Solid Phase Dynamic Extraction also called The Magic Needle (SPDETM - The Magic Needle) by Chromtech Analytical Instruments (Bad Camberg, Germany) belongs to the first group of methods. It is a development of the SPME concept similar to the FFA-SPME and SPME Arrows. A stainless-steel needle in which the sorbent is coated on the inside is used in combination with a gas-tight $2.5-\mathrm{mL}$ syringe. Liquid or HS samples are drawn up into the syringe, thereby forcing the analytes through the stationary phase. After adsorption, the sample is processed using an autosampler for thermal desorption and GC analysis [24].

The in-tube extraction (ITEX) proposed by CTC Analytics AG (Zwingen, Switzerland) is instead an example of the second group of methods, i.e. those that exploit the properties of a packing inside a tube. Specifically, the ITEX system was designed for dynamic HS, followed by thermal desorption prior to GC analysis [23]. Analogously, the extraction needle (NeedlEx), introduced by Shinwa Chemical Industries Ltd (Kyoto, Japan), is made by inserting a sorbent plug inside the needle used for both sampling and injecting in the GC after thermal desorption directly in the GC inlet [25].

A slightly different concept was adopted in the design of HiSorb $^{\mathrm{TM}}$ Sorptive Extraction probes (Markes International Inc., Sacramento, USA). The probes are made by wrapping around a thin rod of inert material, a short sleeve of polydimethylsiloxane rubber which serves as a sorbent phase. The probes were used to isolate analytes from gaseous and aqueous samples before analysis by GC $[26,27]$.

A design similar to the SBSE/Twister ${ }^{\circledR}$ concept led to the development of Monolithic Material Sorptive Extraction (MonoTrap $^{\mathrm{TM}}$ ) based on Merck DGaA monolithic technology (GL Science Inc., Tokyo, Japan). The monolithic-coated bars can be used for sampling liquids and volatile compounds by HS, prior to solvent desorption and GC analysis [28, 29].
Finally, the SniffProbe (Aviv Analytical LTD, Hod Hasharon, Israel) developed by Gordin and Amirav exploits 15-mm long standard $0.53-\mathrm{mm}$ I.D. sections of conventional capillary columns connected to a small pump for sampling gases and vapors. After sampling, the trapping column is placed inside a micro-vial and inserted into the GC injector for thermal desorption and analysis [30].

Other solid-phase microextraction devices have been described in the literature, such as micro-solid-phase extraction ( $\mu \mathrm{SPE})[31]$, adsorptive microextraction $(\mathrm{A} \mu \mathrm{E})[32]$, stir-cake sorptive extraction (SCSE) [33], rotating-disc sorbent extraction (RDSE) [34], and stir-rod sorptive extraction (SRSE) [35]. However, none of the mentioned techniques reached a level of reliability enough to be trusted as a promising product to be presented on the market.

The miniaturization of traditional sample preparation devices for GC led to the development of new analytical instruments and methods that have become more and more also environmentally friendly. Specifically, new instruments include sections that are able to perform simultaneously the operations of sampling, extraction, concentration, and sample introduction in the apparatus. The replacement of conventional analytical systems by miniaturized alternatives in the recent years is remarkable and is perfectly compatible with the growing need of Green Analytical Chemistry (GAC) procedures [36]. The term GAC has been proposed by J. Namiesnik in 2000 [37] and it refers to the role of analytical chemists in making clever combination of environment-friendly and cheap methodologies [38]. Interest in GAC led to the development of eco-scale [39], which evaluates analytical methods' "greenness". An example is the Green Analytical Procedure Index, which qualitatively and quantitatively evaluates the environmental impact of each step of an analytical procedure [40]. Following the " $4 \mathrm{R}$ " concept (reduce, redesign, recovery/recycle, and reuse) for sustainable human activities [41], there are several different ways to make sample preparation "greener".

First, it is necessary to reduce, the amounts of solvents and reagents used in the analysis by redesigning the analytical procedures, and in this respect, the use of miniaturized techniques is undoubtedly a great improvement. Solvent recovery, recycle, and reuse can be implemented in new instruments and are highly recommended. Furthermore, green solvents and reagents, such as agro-solvents, ionic liquids, supercritical fluids, or superheated water, are preferable, rather than petroleum-based solvents. Integration of operations and automation of sample preparation are also important. Moreover, application of factors enhancing the effectiveness of sample preparation as high temperature and/or pressure, microwave and UV radiation, and ultrasound energy has also an impact on the "green" character of the whole procedure [42]. These recommendations are largely met by using chromatographic technologies coupled with devices which operate microextraction and sample injection. Although, generally, the solid-phase microextraction techniques require no polluting solvents in three of these miniaturized techniques, namely, MEPS, SBSE/Twister ${ }^{\circledR}$ solvent Back Extraction (TBE), and MonoTrap ${ }^{\mathrm{TM}}$, microvolumes of solvents improve sample analysis. In these cases, however, the minute sample volume requires only an equivalently minute volume of extraction solvent, which is then introduced almost entirely into the GC system by large volume injection (LVI). Among the various options available for preconcentration, LVI is the most popular and convenient for GC analyses since it can be automated and carried out on line.

The product lines of commercially available, fully-automated miniaturized techniques center around three-axis autosampler systems. In the last 10 years, $x y z$ autosamplers, especially coupled to GC, have proliferated, thus contributing 
to the increase in the usage of hyphenated techniques in analytical chemistry. This has brought about savings on solvents, reduced costs per analysis, faster sample preparation, improved traceability, and full instrument automation. Although most chromatography laboratories already use autosamplers as their standard form of sample injection, this modern instrumentation permits automation beyond just injecting. Modularity and flexibility of these systems can easily be configured to handle both liquid and headspace sampling techniques. Various accessories are available, including barcode reader, robotics change liners and syringe, decapper, heating and stirring modules, and LAN connections to expand overall usability and productivity.

The aim of this review is to report on the state-of-the-art microextraction techniques used for GC, with an emphasis on the description of the 10 systems currently available on the market, given the recent upswing in availability and range of automation techniques.

\section{Literature Search Criteria and Overview of the Results}

Since solid-phase microextraction's birth date in 1989, much literature studies have been produced about microextraction techniques coupled to GC. For reviewing the reports on the subject, we selected the Scopus database (Elsevier, Amsterdam, Netherlands), which is has been the largest collection of peer-reviewed literature published in the fields of science, technology, health, social sciences, and the humanities since 2004. We used structured search strategies based on two concepts: (1) different solid-phase microextraction techniques (both full name and acronym) and (2) gas chromatography. We used Boolean characters "AND" and "OR" (where the acronym or the technique name has a unique meaning) to obtain correct and comprehensive results for each technique. For time frame for our research, we have chosen the period from 1989 to October 7, 2018. No document-type restrictions were applied.

SPME associated with GC was found to be the technique on which more peer-reviewed publications were produced with about 7000 results. SBSE resulted to be the second most popular technique of solid-phase micro-extraction according to the number of publications, with 358 results. For the other techniques coupled to GC, they attest around the dozens of results (70 for MEPS, 26 for $\mathrm{SPDE}^{\mathrm{TM}}, 21$ for MonoTrap ${ }^{\mathrm{TM}}$, 14 for ITEX, 6 for NeedlEx, 4 for SPME Arrow, and 2 for SniffProbe). Interestingly, concerning the Hisorb ${ }^{\mathrm{TM}}$ technique, no peer-reviewed publications could be found, but only application notes released by the producers exist at present. In Figure 1, we show the ten commercially available solid-phase microextraction techniques, and in Figure 2, their trends of publications by year.

The articles for each technique were also divided by subject area. The research areas for each technique listed in decreasing order of number of publications are chemistry and biochemistry, agricultural and biological sciences, environmental, pharmacology and toxicology, and chemical engineering, respectively (Figure 3 ).

This literature study has allowed evidencing the major features in terms of use and customization of each technique. These characteristics are summarized in Table 1.

\section{Theory}

The in-depth discussion of the physics that describes the phenomena which cause the trapping of one analyte into the coating of a fiber is beyond the scope of this review. However, we provide here a short summary of the current knowledge regarding the factors which influence the adsorption and the absorption of analytes from an aqueous and a gaseous phase onto a fiber bearing a solid or a liquid coating as sorbent.

Molecules from liquid phase will be adsorbed in a physical way on a solid surface (active carbon or silica). The activity level of adsorption is based on the concentration of substance, the temperature, and the polarity of the substance. Every kind of solid adsorpting material have its own adsorption isotherm in the water; and this isotherm is definite by the function of Freundlich $[43,44]$.

$$
\frac{x}{m}=K_{f} C_{e}^{1 / n}
$$

where $x / m$ is the adsorbed substance per gram of the adsorbing material, $C_{\mathrm{e}}$ is the concentration difference (between before and after), and $K_{\mathrm{f}}$ and $n$ are the specific constants.

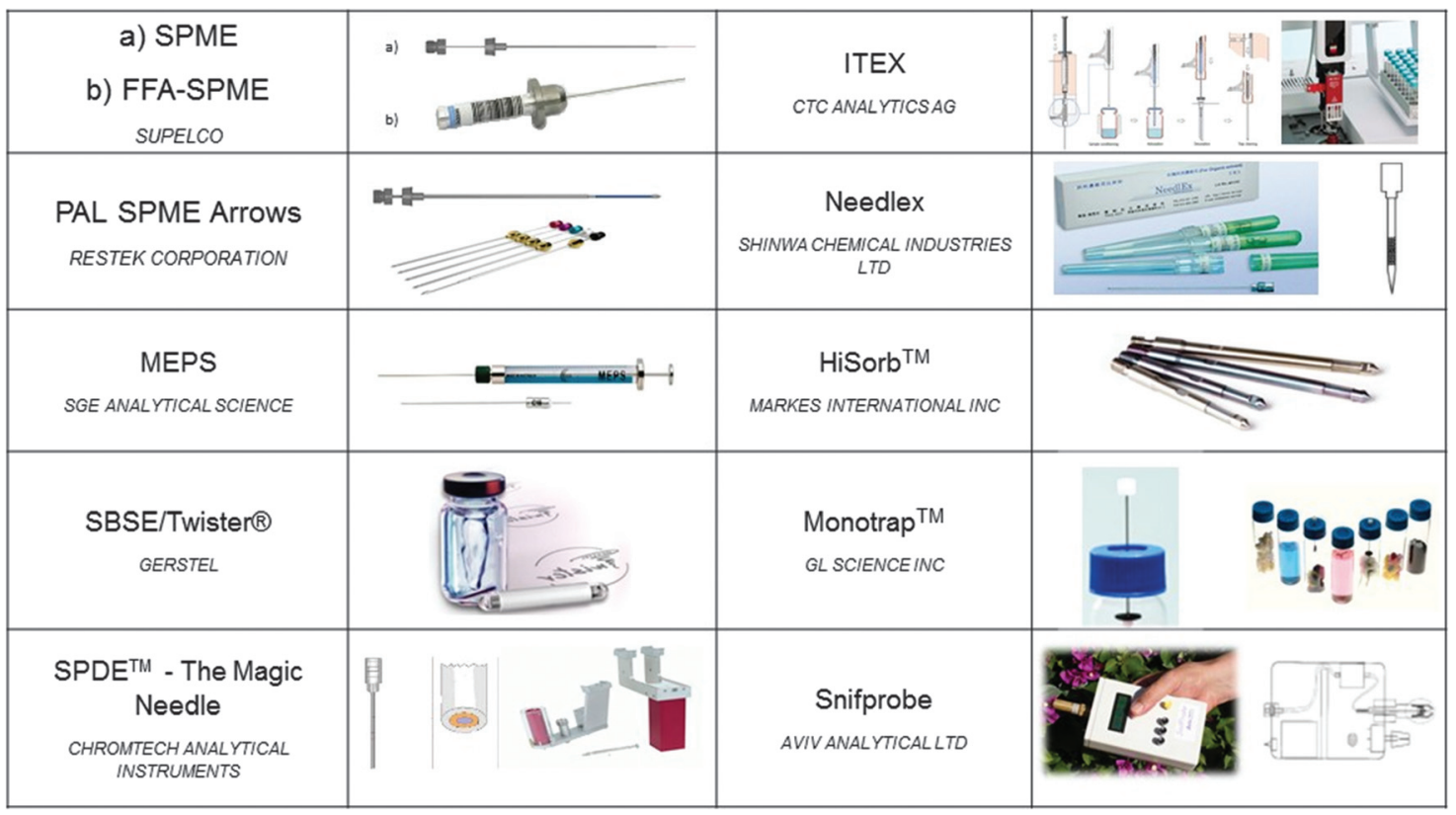

Figure 1. The 10 commercially available solid-phase microextraction techniques 


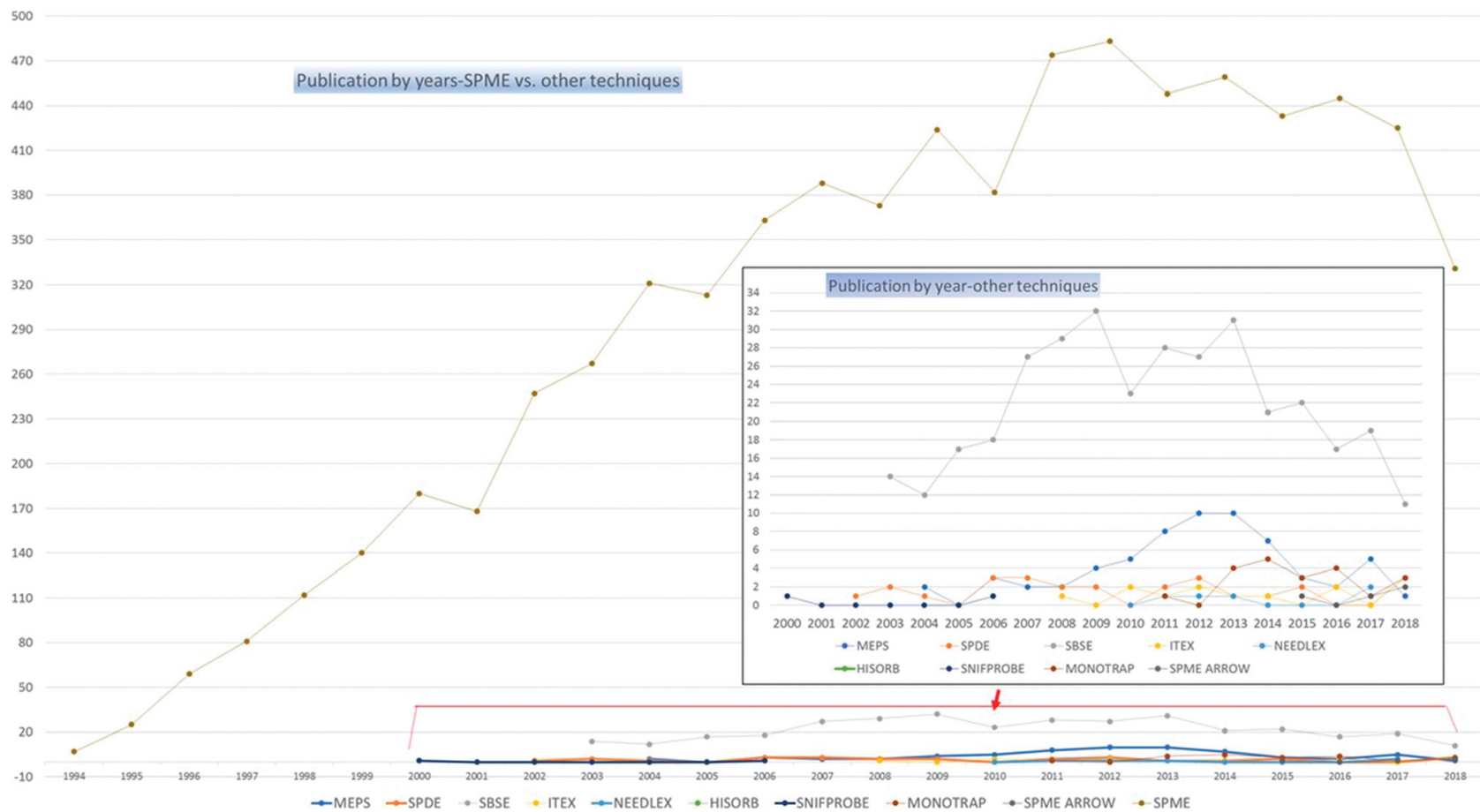

Figure 2. Solid-phase microextraction techniques' trends of publications by year

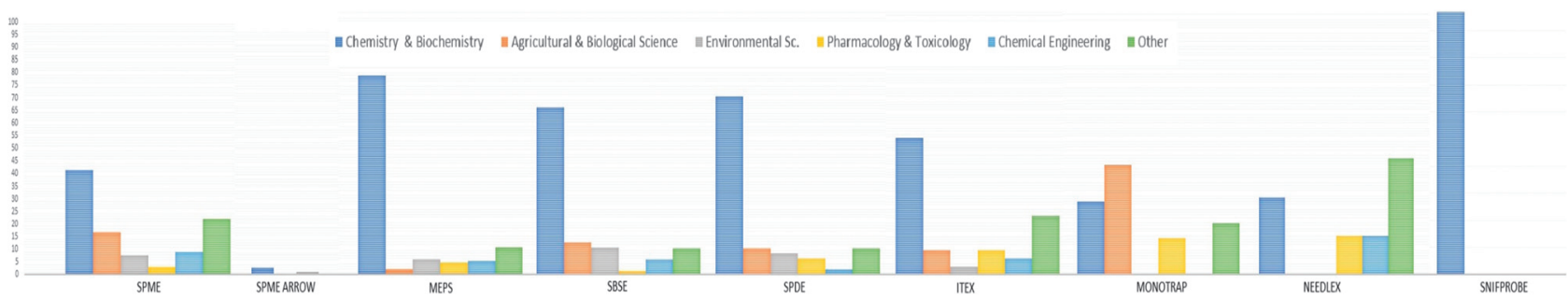

Figure 3. Graphic representation of the solid-phase microextraction techniques' publications by subject area

Instead, the extraction of analytes from air into a solid adsorptive SPME coating fiber has been discussed and modeled by Koziel eighteen years ago by analogy with the process of heat transfer in a cylinder with an axial constant supply of heat [45]. In Koziel's study, the adsorptive sorbent was assumed to be like a cylinder having radius $b$ and length $l$, surrounded by a layer of air having thickness $\delta$ at the boundary with the solid-phase. This model allows the evaluation of the peculiar use of SPME technology as a passive air sampler.

To calculate the theoretical sampling rate (SR) of a porous phase, the theory of heat transfer can be applied [45, 46], expressed as a function of the quantity of heat, which passes through the walls of the tube during a given time $(t)$ :

$$
Q=\left[2 \pi \times 1 \times K_{\mathrm{tc}} \times\left(\Theta_{1}-\Theta_{2}\right) / \ln \left(r_{2} / r_{1}\right)\right] \times t
$$

where $2 \pi \times 1$ is the surface area of the tube, $\ln \left(r_{2} / r_{1}\right)$ is the thickness of the tube, integrated between the limits $r_{1}$ and $r_{2}$ in the infinitesimal progression of the heat, $Q$ is the quantity of heat, $K_{\mathrm{tc}}$ is the coefficient of thermal conductivity, and $\Delta \Theta$ is the temperature difference at the sides of the matrix.

Equation (2) can be used to calculate the mass of the analyte adsorbed in the porous phase; for this purpose, it is necessary to substitute heat $Q$ for the mass $n$ of extracted analyte, the coefficient of heat transfer $K_{\text {tc }}$ for diffusion coefficient $\left(D_{\mathrm{g}}\right.$, the temperature difference $\Delta \Theta$ for the concentration

Table 1. Use and customization of the ten solid-phase microextraction techniques

\begin{tabular}{|c|c|c|c|c|c|c|c|c|c|c|c|c|c|c|c|c|}
\hline & HS & DI & Chemical & Thermal & Absorption & Adsorption & Autor & nation & Different & Multiple & Passive & Active & Dedicate & Bar-code & $\mathrm{GC}$ & $\mathrm{LC}$ \\
\hline & & & desorption & desorption & & & $\begin{array}{l}\text { Two } \\
\text { axes }\end{array}$ & $\begin{array}{l}\text { Three } \\
\text { axes }\end{array}$ & $\begin{array}{l}\text { phases' } \\
\text { availability }\end{array}$ & $\begin{array}{l}\text { sampling } \\
\text { session } \\
\text { capability }\end{array}$ & sampling & sampling & $\begin{array}{l}\text { injection } \\
\text { system }\end{array}$ & reader & & \\
\hline MEPS & $\checkmark$ & $\checkmark$ & $\checkmark$ & & & $\checkmark$ & & $\checkmark$ & $\checkmark$ & & & $\checkmark$ & & & $\checkmark$ & $\checkmark$ \\
\hline SPME Arrow & $\checkmark$ & $\checkmark$ & & $\checkmark$ & $\checkmark$ & $\checkmark$ & $\checkmark$ & $\checkmark$ & $\checkmark$ & & $\checkmark$ & & $\checkmark$ & & $\checkmark$ & \\
\hline SBSE & $\checkmark$ & $\checkmark$ & $\checkmark$ & $\checkmark$ & $\checkmark$ & $\checkmark$ & & $\checkmark$ & $\checkmark$ & $\checkmark$ & $\checkmark$ & & $\checkmark$ & & $\checkmark$ & $\checkmark$ \\
\hline SPDE & $\checkmark$ & $\checkmark$ & & $\checkmark$ & $\checkmark$ & $\checkmark$ & & $\checkmark$ & $\checkmark$ & & $\checkmark$ & $\checkmark$ & & & $\checkmark$ & \\
\hline HiSorb & $\checkmark$ & $\checkmark$ & & $\checkmark$ & $\checkmark$ & & & $\checkmark$ & & & $\checkmark$ & & $\checkmark$ & $\checkmark$ & $\checkmark$ & \\
\hline ITEX & $\checkmark$ & & & $\checkmark$ & & $\checkmark$ & & $\checkmark$ & $\checkmark$ & & & $\checkmark$ & & & $\checkmark$ & \\
\hline NeedlEx & $\checkmark$ & & & $\checkmark$ & & $\checkmark$ & & & $\checkmark$ & & & $\checkmark$ & & & $\checkmark$ & \\
\hline Snifprobe & $\checkmark$ & & & $\checkmark$ & $\checkmark$ & $\checkmark$ & & & $\checkmark$ & & & $\checkmark$ & $\checkmark$ & & $\checkmark$ & \\
\hline
\end{tabular}


difference $\Delta \mathrm{C}$, and the thickness of the tube for the thickness of the phase, expressed by $b$ and $\delta$.

$$
n=\left(\left[2 \pi \times 1 \times D_{g} \times\left\{C_{g}-C_{0}\right\}\right] / \ln [\{b+\delta\} / b]\right) \times t
$$

This complies with Fick's law, where $n$ is the mass of the analyte adsorbed in a sampling time $(t), b$ the radius of the phase, $l$ the length of the phase, $\delta$ the thickness of the boundary layer surrounding the phase, $C_{\mathrm{g}}$ the concentration of the analyte in the bulk air, and $C_{0}$ the concentration of the analyte on the surface of the porous phase. $C_{\mathrm{g}}$ can be regarded as a constant when short sampling time is used, because adsorption binding is instantaneous and the $C_{0}$ is far from saturation.

Under the conditions that the fiber sorbent exposed surface area was equal to $A$, the concentration of the analyte was $C_{\mathrm{g}}$, and the analyte had a gas-phase molecular $D_{\mathrm{g}}$, Koziel estimated the mass of the analyte adsorbed on the porous phase of the SPME fiber over time, $n(t)$, using the equation:

$$
n(t)=\left[\left(D_{g} \cdot A\right) / \delta\right] \cdot C_{g} t
$$

According to this model, the amount of extracted analyte mass $n$, at a given time $t$, being equal the factors $A$ and $C_{\mathrm{g}}$, will be greater for an analyte with a higher $D_{\mathrm{g}}$.

The gas-phase molecular $D_{\mathrm{g}}$, for each analyte, is also an important parameter controlling $\delta$, as illustrated in eq. (5) [45]:

$$
\delta=9.52\left(\operatorname{Re}^{0.62} \cdot \mathrm{Sc}^{0.38}\right)
$$

where the Reynolds number is defined as $\mathrm{Re}=2 u \cdot b / v$ (where $u$ is the linear air speed, $b$ is the radius of the fiber, and $v$ is the air viscosity, $0.014607 \mathrm{~cm}^{2} / \mathrm{s}$ ), and the Schmidt's number is $\mathrm{Sc}=v / D_{\mathrm{g}}$ [45]. Equation (5) is important because it brings a fundamental result that the effective thickness of the boundary layer $\delta$ will be reduced for analytes with lower $D_{\mathrm{g}}$, owing to the inverse proportionality of $\delta$ and the Schmidt's number, Sc.

Considering that the $D_{\mathrm{g}}$ values have been found to be generally directly proportional to temperature and inversely proportional to air pressure [45], the reduction of the boundary layer $\delta$ and the consequent increase of the mass-transfer in a given time for an analyte can thus be achieved in two ways: by increasing the air velocity (which will reduce the Re) or by increasing the air temperature which will cause an increase in $D_{\mathrm{g}}$. Thus, since the temperature increase in turn reduces the sorbent efficiency, no solid coating can be an ideal trapping system for all analytes, and trade-offs are to be considered when sampling.

The absorption of an analyte passing from air into the liquid phase coating of a fiber such as polydimethylsiloxane (PDMS) is described by eq. (6) derived in ref. 47 :

$$
\log K_{1}=a / T+b
$$

where $K_{1}$ is the liquid phase coating/air partition constant (at equilibrium, $K_{1}=C_{\mathrm{PDMS}} / C_{\mathrm{air}}$ [concentration of the analyte in the fiber coating PDMS phase/concentration of the analyte in air $]), a=\Delta H^{\mathrm{V}} / 2.303 R$ and $b=\left[\log \left(R T / \gamma P_{\text {vap }}\right)-\Delta H^{\mathrm{v}} /\right.$ $\left.2.303 R T^{*}\right], \Delta H^{\mathrm{v}}(\mathrm{J} / \mathrm{mol})$ is the analyte heat of vaporization, $R$ is the gas constant $(8.314 \mathrm{~J} / \mathrm{mol} \mathrm{K}), T(\mathrm{~K})$ is the sampling temperature, $\gamma$ is the solute activity coefficient, $P_{\text {vap }}(\mathrm{Pa})$ is the vapor pressure, and $T^{*}$ is the known temperature coefficient. As can be seen from eq. (6), the amount of analyte trapped into the liquid coating of the fiber is not dependent on the air flow.

The $K$ absorptive coating values could be determined by linear temperature programmed retention indices (LTPRI). LTPRI is a system which indexes compounds' retention times relative to the retention times of $n$-alkanes. This system is applicable to retention times for temperature-programmed gas-liquid chromatography. The logarithm of the coating-to-air distribution constants of $n$-alkanes can be expressed as a linear function of their LTPRI numbers. If LTPRI numbers are available in the literature, we can estimate $K$ values accurately, without experimental, while if the LTPRI number for a compound is not available, it can be calculated from a GC run, with this equation.

$$
\mathrm{LTPRI}=(100 N)\left[100 \times\left(t_{r(a)}-t_{r(n)}\right) /\left(t_{r(n+1)}-t_{r(n)}\right)\right]
$$

where $N$ is the number of carbon atoms for $t_{\mathrm{r}(n)}, t_{\mathrm{r}(\mathrm{a})}$ is the analyte retention time, $t_{\mathrm{r}(\mathrm{n})}$ is the $n$-alkanes retention time less than $t_{\mathrm{r}(\mathrm{a})}$, and $t_{\mathrm{r}(\mathrm{n}+1)}$ is the $n$-alkanes retention time higher than $t_{\mathrm{r}(\mathrm{a})}$. Note that to determine the LTPRI, the GC column should be coated with the same material as the sorptive coating.

Where diffusion chamber is available, the SR of a microextraction sampler, can be expressed as [48]:

$$
\mathrm{SR}=D_{g} \times(A / Z)
$$

where $Z$ is the distance from the sampling surface, $A$ is the surface of the extractive phase, and $D_{\mathrm{g}}$ is the analyte diffusion coefficient.

Two extraction modes can be used to isolate analytes from a complex matrix: direct immersion (DI) extraction and HS. In DI extraction, the extractive phase is directly immersed in liquid samples. In HS, the extractive material is exposed in the vapour phase above a gaseous, liquid, or solid sample. In the case of DI extraction from an aqueous solution, we have only two phases involved, and the mass of analyte adsorbed by the coating is described by equation [47]:

$$
n=\left(C_{0} \cdot V_{1} \cdot V_{2} \cdot K\right) /\left(K \cdot V_{1}+V_{2}\right)
$$

where $C_{0}$ is the initial concentration of the analyte in the aqueous solution, $V_{1}$ and $V_{2}$ are the volumes of the coating and of the aqueous solution, and $K$ is the partition coefficient of the analyte between the sorptive coating and the aqueous solution [47]. This equation is useful to illustrate the important rule of thumb applied when using microextraction techniques for DI sampling, in which the partition coefficients of the analyte between the phases involved in the sampling process can anticipate the trend in solid-phase microextraction efficiency.

As regards HS, according to Zhang and Pawliszyn [49] for extractive materials coated with either a solid or a liquid film, the mass $(n)$ of analytes adsorbed at the equilibrium in 3 phases system, in which the coating is exposed to a HS and an underlying aqueous solution, is related to the overall equilibrium of partition of the analytes between the three phases, consisting of the sorptive coating (liquid or solid), the HS, and the aqueous solution:

$$
n=\left(C_{0} \cdot V_{1} \cdot V_{2} \cdot K_{1} \cdot K_{2}\right) /\left(K_{1} \cdot K_{2} \cdot V_{1}+K_{2} \cdot V_{3}+V_{2}\right)
$$

where $C_{0}$ is the initial concentration of the analyte in the aqueous solution, $V_{1}, V_{2}$ and $V_{3}$ are the volumes of the coating, the 
aqueous solution, and the HS, respectively, $K_{1}$ is the phase coating/HS partition coefficient $\left(K_{1}=C_{1} / C_{3}\right)$, and $K_{2}$ is the HS/aqueous matrix partition coefficient $\left(K_{2}=C_{3} / C_{2}\right)$.

From the above discussion, it appears that microextraction techniques can be seen as methods relying on partition equilibria between two or three phases (coating, HS, and aqueous solution), depending on the type of sampling that is concerned. The extraction efficiency will be dependent on the completion of the equilibrium, i.e., the reaching of homogeneous concentration of the analyte within each of the phases and the concentration differences between each two phases in contact, satisfying the values of their partition coefficient [49].

When sampling volatile organic analytes and most organic compounds by HS using a PDMS absorptive liquid coating, for instance, it must be kept in mind that these compounds have small phase coating/HS partition coefficient $K_{1}$ and generally $K_{1}>K_{2}$, thus making $\mathrm{K}$ an overall small number [49]. Therefore, the amount of analyte extracted by the coating will be negligible compared to the amount of analyte initially present in the HS. This in turn means that the concentration of the analyte in the aqueous solution will be unmodified during and after the extraction. Thus, the extraction time will be determined exclusively by the diffusion of the analyte from the aqueous to the HS vapour phase. On the other hand, non-volatile analytes have a small $K_{2}$ value, i.e., a small HS/aqueous matrix partition coefficient value. Therefore, Henry's constant, $K_{\mathrm{H}}=K_{2} \cdot R T$, will be small, and the concentration of the analyte in the HS will be low. In this case, the HS extraction will change the concentration of the analyte in the aqueous phase, and the sampling process will take longer times to reach the equilibrium.

Partition coefficients between the phases are often reported on databases of physical-chemical data [50-53] or can be hypothesised starting from the octanol-water partition coefficient $\left(K_{\text {ow }}\right)$ and Henry's constant $\left(K_{\mathrm{H}}\right)$ values for a given analyte.

All microextraction technologies listed in the previous section can be used for HS and DI, except for ITEX, Needlex, and Snifprobe which can only be used for HS extraction. In general, DI is more effective than HS for compounds present in a liquid medium. DI is suitable for the extraction of semior non-volatile analytes in liquid samples. Performing extraction in the HS is ideal, instead, for those analytes which have a partition coefficient sufficiently high into the headspace of the sample: volatile compounds are enriched in the HS and extracted, while the majority of the matrix components remain in the aqueous phase. In order to obtain good results with HS, control of the extraction conditions such as the sample mixing/stirring and sampling temperature and time are of paramount relevance [54]. The extraction performance of these different techniques depends on the properties of the analytes and the sample matrix.

$\mathrm{Ad} /$ absorption is modulated by the concentration of the analyte in the matrix, the thickness of the sorbent phase coating, the temperature, and the difference in chemical nature (e.g., polarity, hydrophobicity, and volatility) between the analyte, the matrix, and the sorbent material. Thus, for instance, a polar analyte will poorly be captured by active charcoal, whereas a non-polar analyte can be recovered almost quantitatively by active charcoal. The adsorptive or retentive properties of bonded silica are instead due not only to the functional groups bonded to the silica substrate, but also to the polar character of the silica itself and to free underivatized silanols remaining on the surface after the production of the sorbent.

These observations suggest that depending on the type of analyte and of sampling (be it HS or DI), all the mentioned factors (i.e., analytes volatility, hydrophobicity, partition coefficients in the different phases, and so on) should be considered in order to select the more efficient sampling system [49]. Molecules from a gaseous or liquid matrix will be ad/ absorbed onto the surface of the sorbent used for sampling (e.g., made of active carbon/charcoal, silica, or PDMS) as a consequence of a complex multifactorial mechanism. This observation is crucial when undertaking method development because it points clearly to the need of using multifactorial statistical approaches for this task such as Design of Experiments.

\section{Microextraction Method Development and Design of Experiments}

The theory of sampling reported in the previous section evidences that a number of factors are relevant for the success of microextraction experiments. The factors involved of course depend also on the type of device used for sampling and on the goal of the analysis, and this adds complexity to the study of method development. For these reasons, the set-up of a method for microextraction by heuristic trial-and-error or onevariable-at-a-time (OVAT) approaches can be very frustrating and expensive in terms of time and resources. Therefore, several authors chose, in the last years, to use the multivariate statistical approach known as design of experiments (DoE) in order to be guaranteed that method development would at least provide a robust procedure for sampling while saving time, labor, and money $[55,56]$. The number of the papers reporting on microextraction methods and DoE published since the first review on the subject by Stalikas in 2009 [57] is quite high and would require a dedicated review to illustrate fairly the subject. We report here only on a few selected reviews published starting from the year 2009 and would like to address the interested reader to these publications for more information on microextraction method development and DoE.

Stalikas and coworkers [57] reported on the chemometric approaches available to optimize and assess the validity and the robustness of microextraction procedures. Their comprehensive review discusses the results of about 40 applications of microextraction studied using DoE, illustrating the choice of the experimental design, together with a critical appraisal of the data presented.

Hibbert in 2012 published a comprehensive review on the use of DoE in chromatography in the form of a tutorial article. In this review, all aspects of the application of DoE to chromatographic method development are thoroughly examined including terminology of DoE, aims of DoE, and problems informed by DoE (screening of factor, response surface design, and robustness testing), and common types of designs applicable to microextraction prior to chromatographic analysis [58].

In 2016, Hecht and coworkers published a review on the use of DoE in mass spectrometry practices [59]. Several examples of microextraction methods studied with DoE are reported, together with an interesting overview on GC-mass spectrometry (MS) applications using microextraction techniques.

\section{Robotics Automation}

Automated, unattended sample preparation can increase laboratory throughput and provide results of precision superior to manual-operated instruments. Robotic autosamplers and workstations perform automated sample preparation procedures that range from simple dilution to complicated derivatization. CTC Analytics AG (Zwingen, Switzerland) was the first company to offer commercial $x y z$ autosamplers for GC; the A200S, the first GC liquid autosampler, was released on the market in 1986 [60]. Subsequently, CTC Analytics produced the PAL system platform in 1998 [61], expanded it into the HTX PAL 
Table 2. Commercially available autosamplers and related usable solid-phase microextraction techniques

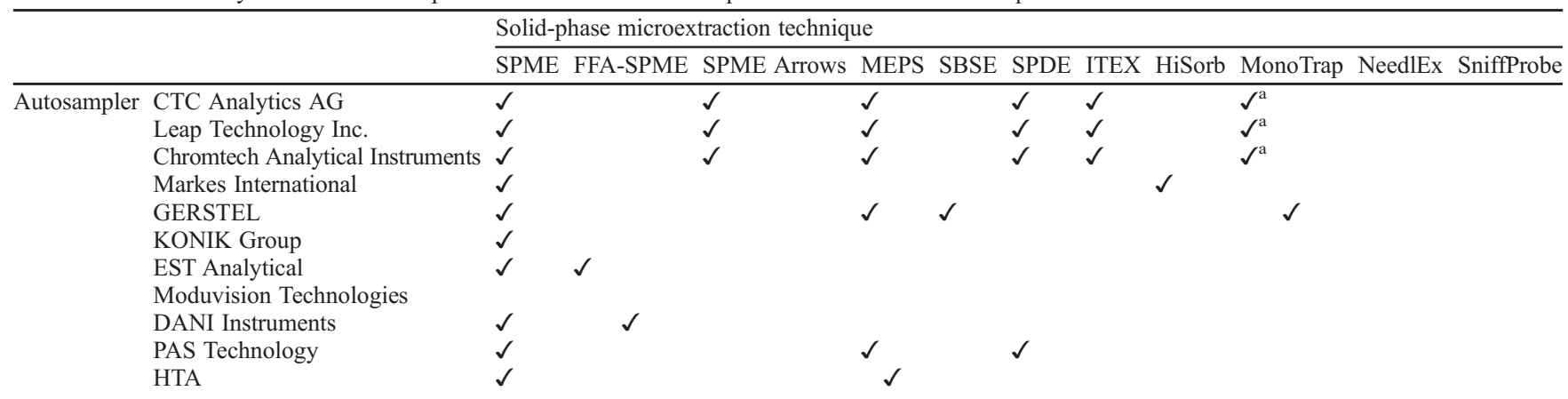

${ }^{a}$ CTC Analytics AG, Leap technology Inc., and Chromtech Instruments, upgraded with an Optica 4-Multimode inlet with a thermal desorption unit, can managed capped desorption tube with LINEX-Liner Exchanger (GL Science B.V., Eindhoven, Netherlands) in complete automation.

offering an extended $x$-range in 2003, and brought out its PAL RTC, RSI, and LSI systems between 2012-2014 [62]. Basically, this Swiss company made history with its $x y z$ autosamplers.

Other front-end automation solutions, all of which are based on CTC Analytics' instruments, are nowadays produced by Leap Technology Inc. (Trajan Scientific and Medical, Ringwood Victoria, Australia) [63], Chromtech Analytical Instruments (Bad Camberg, Germany), Markes International Inc. (Sacramento, USA), and GERSTEL GmbH \& Co. KG (Mülheim an der Ruhr, Germany) [64].

Some companies proposed new autosamplers recently on the market: specifically, ROBOKROM (KONIK Group, Barcelona, Spain), FLEX (EST Analytical, Fairfield, USA), Primariz (Moduvision Technologies, Vlissingen, Netherlands), Master (DANI Instruments, Cologno Monzese, Italy), and CONCEPT MIS (PAS Technology, Magdala, Germany). Interestingly, HTA (Brescia, Italy) has also produced the HT2800T, a next-generation two-axis autosampler. All these systems can be customized to meet the requirements of several different analytical methods and are designed to increase the work-flow productivity (Table 2).

Nowadays simplifying method development and enhancing the productivity of routine analysis by allowing samples to be run without interruption 24/7 while delivering accurate results are the main forces that drive the work of analytical instrumentation engineers. SPME, Twister ${ }^{\circledR}$, and MonoTrap ${ }^{\text {TM }}$ have proven to be among the most performing and versatile devices for environmental sampling, in particular for air sampling [65-69]. To face the needed of high-throughput analytical sessions, special systems for these microextraction techniques, Multi Fiber eXchange (MFX, EST, Fairfield, USA) for SPME fibers and Thermal Desorption Unit tray (Gerstel, Mülheim an der Ruhr, Germany) for Twister ${ }^{\circledR}$ and MonoTrap ${ }^{\text {TM }}$, were developed; they allow not only on-line sampling and injecting but also the upload of multiple samplers, which once sampled off-line and can then processed in complete automation, thanks to the dedicated autosampler systems [70].

\section{Sensitive and High Throughput GC Analysis: Large Volume Injection and Fast GC}

The first LVI in GC was proposed by Abel [71] and developed by Vogt et al. in 1979 [72]; this technique has been readapted in recent years to include the growing use of miniaturized sample preparation and increasingly-efficient three-axis autosamplers. The advantages of LVI over other techniques consist in decreased analyte discrimination, better recoveries of thermolabile compounds, and less pronounced adverse effects of non-volatiles present in the sample on the injection process [73]. The most important feature of LVI is that it introduces large volumes of samples (up to hundreds $\mu \mathrm{L}$ ) into
GC system and thus increase the method's sensitivity [74]. Currently, available LVI methods involve various injection modes, namely: programmed-temperature vaporizing (PTV) solvent split, on-column injection (OCI), direct sample introduction (DSI)/difficult matrix injection (DMI), splitless overflow/concurrent solvent recondensation (CSR), AT-column, through-oven transfer adsorption desorption (TOTAD), and a stomach-shaped insert liner. New injectors for LVI have recently been marketed, while the availability of inert packing materials has optimized procedures and extended the application range towards more labile and adsorptive analytes. This injection system is applicable to both conventional GC and fast GC, in order to develop high productivity methods [75-79].

Fast GC has received renewed attention in the past two years. New GC instruments and accessories in 2015-2018 include more capabilities for fast GC than their predecessors, such as rapid oven heating and cooling, extended inlet pressures, support for hydrogen carrier gas, and faster detector response times [80]. Beyond these basics, workflow features such as ease of changing columns, energy efficiency, reduced maintenance, and improved user interfaces also have garnered significant attention. Fast GC has the potential to be a powerful tool in routine analytical laboratories by increasing sample throughput and improving laboratory efficiency. The advantages of using fast GC are various: first of all, the increased laboratory throughput resulting in the reduced cost per analysis and the required time to get results. Furthermore, one of the most important application of this system is when it is coupled with field-portable GC instruments, in situations where the results of the analysis are needed close to where the answer is needed (e.g., on-site environmental and industrial hygiene applications) [81]. Several options can be considered to enhance the speed of fast GC: columns, GC's pressure, and temperature programming [82]. Analysis times are also decreased by using high carrier gas linear velocities. The loss in resolution caused by the manipulation of these options is offset by using: narrow internal diameter columns, hydrogen carrier gas, low film thickness. Many of these parameters are related to each other; therefore, all parameters must be evaluated to make sure they are set correctly. The Pro EZGC Chromatogram Modeler software [83], a new chromatogram modelling software developed by Restek Corporation (State College, USA), makes scenarios for optimizing and speeding up complex mixture separations easy to be tested out. Nowadays fast GC can be performed on commercial GCs, which are normally equipped with high-speed injection systems, electronic gas pressure control, rapid oven heating/cooling, and fast detection [84]. The recent commercial innovations are related to the following: Trace 1300 by ThermoFisher Scientific (Waltham, USA) [85], Nexis GC 2030 by Shimadzu (Kyoto, Japan) [86], Master GC by DANI Instruments 
(Cologno Monzese, Italy), and Clarus SQ 8 by PerkinElmer (Waltham, USA) [87]. Agilent technologies (Santa Clara, USA) has developed a peculiar GC system, Intuvo 9000, which allows ultra-fast GC by eliminating column maintenance and by enabling rapid change columns with click-andrun connections [88]. Thanks to its versatility, fast GC has different fields of application: environmental [89], petroleum/ chemical [90, 91], food and beverage [92], occupational medicine [93], flavor and fragrance [94], and clinical [95]. Solidphase microextraction techniques perfectly match the fast GC. Narrow internal diameter columns have lower sample capacity compared to conventional GC column dimensions, and to prevent peak shapes from being distorted, a smaller amount of sample and solvent must be introduced: criteria perfectly respected by the cited techniques, both during sampling and thermal or chemical desorption.

\section{Conclusions}

The aim of this review was to give an overview of the role of miniaturized techniques of extraction that can be used prior to GC analysis. Our study suggests that automated solid-phase microextraction techniques coupled with GC are a viable solution for many different analytical needs. Miniaturized systems offer several advantages, such as short analysis time, the need of small sample volumes, easy hyphenation with GC-MS, and minimal waste production. To date, customized, highly automated GC apparatuses for high-throughput screening not only are user-friendly but also reduce costs. The application of automated solid-phase microextraction techniques in the analysis' preliminary steps allows the reduction of time-consuming manual sample preparation, as well as limits the impact of chemicals on the environment, thus providing greener analytical tools. These new sample handling techniques are currently increasingly explored because of the considerable need for information management and the integration of data management into the analytical process.

\section{References}

1 Marketsandmarkets.com, Gas Chromatography Market by Instrument (Systems, Detectors), Accessories and Consumables (Columns, Column accessories, Pressure regulators, Gas generators), End user (Oil \& Gas industry, Environmental agencies, Pharma \& Biotech) - Global Forecast to 2022. [online] Available at: https://www.marketsandmarkets.com/ PressReleases/gas-chromatography.asp [Accessed November 2018], 2018.

2 Marketsandmarkets.com, High-performance Liquid Chromatography (HPLC) Market by Product (Instruments (Systems, Detectors), Consumables (Columns, Filters), and Accessories), Application (Clinical Research, Diagnostics, Forensics) - Analysis \& Global Forecast to 2021 [online] Available at: https: //www.marketsandmarkets.com/PressReleases/hplc.asp [Accessed 5 November 2018], 2018.

3 Grandviewresearch.com, Gas Chromatography (GC) Market Size | Global Industry Report, 2025. [online] Available at: https://www. grandviewresearch.com/industry-analysis/gas-chromatography-market [Accessed 5 November 2018], 2018.

4 Factmr.com, Global Gas Chromatography Market - Fact.MR. [online] Available at: https://www.factmr.com/media-release/183/gas-chromatographymarket [Accessed 5 November 2018], 2018.

5 Sharma, S.; Plistil, A.; Simpson, R. S.; Liu, K.; Farnsworth, P. B.; Stearns, S. D.; Lee, M. L. J. Chromatogr. A 2014, 1327, 80-89.

6 Gałuszka, A.; Migaszewski, Z. M.; Namieśnik, J. Environ. Res. 2015, 140, 593-603.

7 Jehlička, J.; Culka, A.; Bersani, D.; Vandenabeele, P. J. Raman Spectrosc. 2017, 48, 1289-1299.

8 Harshman, S. W.; Rubenstein, M. H.; Qualley, A. V.; Fan, M.; Geier, B. A.; Pitsch, R. L.; Slusher, G. M.; Hughes, G. T.; Dershem, V. L.; Grigsby, C. C.; Ott, D. K.; Martin, J. A. Int. J. Environ. Anal. Chem. 2017, 97, 247-263.

9 Arthur, C. L.; Pawliszyn, J. Anal. Chem. 1990, 62, 2145-2148.

10 Martos, P. A.; Saraullo, A.; Pawliszyn, J. Anal. Chem. 1997, 69 , 402-408.

11 Martos, P. A.; Pawliszyn, J. Anal. Chem 1998, 70, 2311-2312.

12 Yu, X.; Pawliszyn, J. Anal. Chem. 2000, 72, 1788-1792.

13 Marini, F.; Bellugi, I.; Gambi, D.; Pacenti, M.; Dugheri, S.; Focardi, L.; Tulli, G. Acta Anaesthesiol. Scand. 2007, 51, 625-632.
14 Dugheri, S; Bonari, A., Pompilio, I., Mucci, N., Montalti, M., Arcangeli, G. Rasayan J. Chem. 2016, 9, 657-666.

15 Handley, J.; Harris, C. M. Anal. Chem. 2001, 73, 660

16 Pacenti, M.; Dugheri, S.; Gagliano-Candela, R.; Strisciullo, G.; Franchi, E.; Degli Esposti, F.; Perchiazzi, N.; Boccalon, P.; Arcangeli, G.; Cupelli, V. Acta Chromatogr. 2009, 21, 379-397.

17 Helin, A.; Rönkkö, T.; Parshintsev, J.; Hartonen, K.; Schilling, B.; Läubli, T.; Riekkola, M. L J. Chromatogr. A 2015, 1426, 56-63.

18 Altun, Z.; Abdel-Rehim, M.; Blomberg, L. G. J. Chromatogr. B 2004, $813,129-135$.

19 Abdel-Rehim, M. Anal. Chim. Acta 2011, 701, 119-128.

20 Mahdi, M. M.; Abdel-Rehim, A.; Abdel-Rehim, M. TrAC, Trends Anal. Chem. 2015, 67, 34-44.

21 León, V. M.; Alvarez, B.; Cobollo, M. A.; Munoz, S.; Valor, I. J. Chromatogr. A 2003, 999, 91-101.

22 Sánchez-Rojas, F.; Bosch-Ojeda, C.; Cano-Pavón, J. M. Chromatographia 2009, 69, 79-S94.

23 Jochmann, M. A.; Yuan, X.; Schilling, B.,Schmidt, T. C. J. Chromatogr. A 2008, 1179, 96-105.

24 Bicchi, C.; Cordero, C.; Liberto, E.; Rubiolo, P.; Sgorbini, B. J. Chromatogr. A 2004, 1024, 217-226.

25 Lee, X.; Huang, D.; Lou, D.; Pawliszyn, J. J. Sep. Sci. 2012, 35 , $1675-1981$.

26 Application Brief Released: October 2016, Markes International, https:// kinesis-australia.com.au/media/wysiwyg/knowledebase/pdf/Flavour_profiling of various drinks using HiSorb_sorptive extraction and TD GC MS.pdf.

27 Burger, B. V.; Marx, B.; Le Roux, M.; Burger, W. J. G. J. Chromatogr 2006, 1121, 259-267.

28 Jang, H. J.; Son, H. H.; Lee, D. S. Bull. Korean Chem. Soc. 2011, 32, 4275-4280.

29 Goudsmits, E.; Sharples, G. P.; Birkett, J. W. J. Forensic Sci. Res. 2017, $1,68-76$.

30 Gordin, A.; Amirav, A. J. Chromatogr. A 2000, 903, 155-172.

31 Battle, K. N.; Jackson, J. M.; Witek, M. A.; Hupert, M. L.; Hunsucker, S. A.; Armistead, P. M.; Soper, S. A. Analyst 2014, 139, 1355-1363.

32 Neng, N. R.; Silva, A. R. M.; Nogueira, J. M. F. J. Chromatogr. A 2010, 1217, 7303-7310.

33 Huang, X.; Chen, L.; Yuan, D.; Bi, S. J. Chromatogr. A 2012, 1248, $67-73$.

34 Jachero, L.; Ahumada, I.; Richter, P. Anal. Bioanal. Chem. 2014, 406, 2987-2992.

35 Luo, Y. B.; Ma, Q.; Feng, Y. Q. J. Chromatogr. A 2010, 1217, 3583-3589.

36 Nascimento, M. M.; Rocha, G. O.; Andrade, J. B. Sci. Rep. 2017, 7 , 2267

37 Namiesnik, J. Environ. Sci. Pollut. Res. 1999, 6, 243.

38 Turner, C. Pure Appl. Chem. 2013, 85, 2217-2229.

39 Armenta, S.; Garrigues, S.; de la Guardia, M. TrAC, Trends Anal. Chem. 2015, 71, 2-8

40 Płotka-Wasylka, J. Talanta 2018, 181, 204-209.

41 Kirchherr, J.; Reike, D.; Hekkert, M. Resour. Conserv. Recy. 2017, 127, 221-232.

42 Perino, S.; Petitcolas, E.; De La Guardia, M.; Chemat, F. J. Chromatogr A 2013, 1315, 200-203.

43 Kushwaha, A. K.; Gupta, N.; Chattopadhyaya, M. C Arab. J. Chem. 2017, 10, S81-S89.

44 Aklil, A.; Mouflih, M.; Sebti, S. J. Hazard Mater. 2004, 112, 183-190.

45 Koziel, J.; Jia, M.; Pawliszyn, J. Anal. Chem. 2000, 72, 5178.

46 Lienhard IV, J. H.; Lienhard V, J. H. A Heat Transfer textbook 3rd edn, Phlogiston press, Cambridge, 2004, 2, 50-64.

47 Martos, P.; Pawliszyn, J. Anal. Chem. 1997, 69, 206.

48 Palmes, E. D.; Gunnison, A. F. Am. Ind. Hyg. Assoc. J. 1973, 34, 78

49 Zhang, Z.; Pawliszyn, J. Anal. Chem. 1993, 65, 1843-1852.

50 toxnet.nlm.nih.gov, National Library of Medicine, ChemLDplus.[online]

Available at: https://chem.nlm.nih.gov/chemidplus/chemidlite.jsp [Accessed

8 November 2018], 2018.

51 epa.gov, US Environmental Protection Agency, EPA on-line tools for site assessment calculation. [online] Available at: https://www3.epa.gov/ ceampubl/learn2model/part-two/onsite/ [Accessed 8 November 2018], 2018.

52 ddbst.de, Dortmund Data Bank [online] Available at: http://www.ddbst.

de/ [Accessed 8 November 2018], 2018.

53 archemcalc.com, SPARC Performs Automated Reasoning in Chemistry [online] Available at: http://www.archemcalc.com/sparc.html [Accessed 8 November 2018], 2018.

54 Kataoka, H.; Lord, H. L.; Pawliszyn, J. J. Chromatogr. A 2000, 880, $35-62$.

55 Leardi, R. Anal Chim Acta 2009, 652, 161-172.

56 Ebrahimi-Najafabadi, H.; Leardi, R.; Jalali-Heravi, M. J. AOAC Int 2014, $97,3-11$

57 Stalikas, C.; Fiamegos, Y.; Sakkas, V.; Albanis, T. J. Chromatogr. A 2009, 1216, 175-189.

58 Hibbert, D. B. J. Chromatogr. B 2012, 910, 2-13.

59 Hecht, E. S.; Oberg, A. L.; Muddiman, D. C. J. Am. Soc. Mass Spectrom. 2016, 27, 767-785

60 ctc.chm, [online] Available at: https://www.ctc.ch/index.php?id=142, [Accessed 19 November 2018], 2018.

61 O'Reilly, J.; Wang, Q.; Setkova, L.; Hutchinson, J. P.; Chen, Y.; Lord, H. L.; Pawliszyn, J. J. Sep. Sci. 2005, 28, 2010-2022.

62 Palsystem.com, [online] Available at: https://www.palsystem.com/ fileadmin/public/docs/Downloads/Brochures/PAL_RTC-RSI_Rev2_web.pdf [Accessed 9 November 2018], 2018.

63 Calafat, A. M.; Stanfill, S. B. J. Chromatogr. B 2002, 772, 131-137. 
64 Bianchi, F.; Dugheri, S.; Musci, M.; Bonacchi, A.; Salvadori, E.; Arcangeli, G.; Carini, M. Anal. Chim. Acta 2011, 707, 197-203.

65 Koziel, J. A.; Pawliszyn, J. J. Air Waste Manag. Assoc. 2001, 51 , $173-184$.

66 Pieraccini, G.; Bartolucci, G.; Pacenti, M.; Dugheri, S.; Boccalon, P.; Focardi, L. J. Chromatogr. A 2002, 955, 117-124.

67 Wennrich, L.; Popp, P.; Hafner, C. J. Environ. Monit. 2002, 4, 371-376.

68 Gómez-Ríos, G. A.; Reyes-Garcés, N.; Pawliszyn, J. J. Sep. Sci. 2015, $38,3560-3567$.

69 Shimadzu.com, [online] Available at: https://solutions.shimadzu.co.jp/an n/en/gcms/ipo215061.pdf [Accessed 10 October 2018], 2018.

70 Dugheri, S.; Bonari, A.; Gentili, M.; Cappelli, G.; Pompilio, I.; Bossi,

C.; Arcangeli, G.; Campagna, M.; Mucci, N. Molecules 2018, 23.

71 Abel, K. J. Chromatogr. 1964, 13, 14-21.

72 Vogt, W.; Jacob, K.; Ohnesorge, A. B.; Obwexer, H. W. J. Chromatogr.

1979, 186, 197-205.

73 Godula, M.; Hajšlová, J.; Maštouska, K.; Křivánková, J. J. Sep. Sci. 2001, 24, 355-366.

74 Dugheri, S.; Bonari, A.; Cappelli, G.; Pompilio, I.; Bossi, C.; Mucci, N.; Arcangeli, G. Chin. J. Chromatogr. 2018, 36, 1311-1322.

75 Companioni-Damas, E. Y.; Santos, F. J.; Galceran, M. T. Talanta 2014 $118,245-252$.

76 Backe, W. J.; Yingling, V.; Johnson, T. J. Chromatogr. A 2014, 1334, $72-78$

77 Ross, A. R.; Liao, X. Anal. Chim. Acta 2015, 889, 147-155.

78 Terán-Baamonde, J.; Bouchet, S.; Tessier, E.; Amouroux, D. J. Chromatogr. A 2018, 1547, 77-85.

79 Kirchner, M.; Matisová, E.; Hrouzková, S.; Húšková, R. Pet. Coal 2007, 49, 72-79

80 Hinshaw, J. V. LCGC North America 2017, 35, 11, 810-815.

81 Dömötörová, M.; Matisová, E. J. Chromatogr. A 2008, 207, 1-2, 1-16.
82 Matisová, E.; Dömötörová, M. J. Chromatogr. A 2003, 1000, 1-2, 199-221.

83 restek.com, Pro EZGC Chromatogram Modlere [online] Available at: http://www.restek.com/proezgc) [Accessed 10 November 2018], 2018.

84 Korytár, P.; Janssen, H.; Matisová, E.; Brinkman, U. A. Th. Trends Analyt. Chem. 2002, 21, 9-10, 558-572.

85 Termofisher.com, [online] Available at: https://assets.thermofisher.com TFS-Assets/CMD/Specification-Sheets/PS-52260-TRACE-1300-GC-PS52260EN.pdf [Accessed 9 November 2018], 2018

86 Shimadzu.com, [online] Available at: file://C:/Users/salie/Downloads/ Fragrance_Shimadzu_032_gcms_datasheet.pdf [Accessed 9 November 2018], 2018

87 perkinelmer.com. [online] Available at: https://www.perkinelmer.com/ CMSResources/Images/44-129699BRO_ClarusSQ8Brochure.pdf. [Accessed 5 November 2018], 2018.

88 Agilent.com, [online] Available at: https://www.agilent.com/cs/library/ slidepresentation/public/Fast GC Methods ISCC Agilent 2017.pdf [Accessed 9 November 2018], 2018.

89 Muir, D.; Sverko, E. Anal. Bional. Chem. 2006, 386, 769-789.

90 Striebich, R. C.; Motsinger, M. A.; Rauch, M. E.; Zabarnick, S.; Dewitt, M. Energy Fuels 2005, 19, 2445-2454.

91 Pacenti, M.; Lofrumento, C.; Dugheri, S.; Zoppi, A.; Borsi, I.; Speranza, A.; Boccalon, P.; Arcangeli, G.; Antoniucci, A.; Castellucci, E. M.; Cupelli, V. Eur. J. Inflamm. 2009, 7, 25-37.

92 Masood, A.; Stark, K. D.; Salem, N. J. Lipid Res. 2005, 46, 2299-2305.

93 Pacenti, M.; Dugheri, S.; Traldi, P.; Degli Esposti, F.; Perchiazzi, N., Franchi, E.; Calamante, M.; Kikic, I.; Alessi, P.; Bonacchi, A.; Salvadori, E.; Arcangeli, G.; Cupelli, V. J. Anal. Methods. Chem. 2010.

94 Mondello, L.; Casilli, A.; Tranchida, P. Q.; Cicero, L.; Dugo, P.; Dugo, G. J. Agric. Food Chem. 2003, 51, 5602-5606.

95 Buyer, J. S. J. Microbiol. Methods 2002, 51, 209-215. 